\title{
Objective Selection of Sensitive Species Indicative of Pollution-Induced Change in Benthic Communities. I. Comparative Methodology
}

\author{
John S. Gray ${ }^{1}$ and T. H. Pearson ${ }^{2}$ \\ ${ }^{1}$ Institult for Marinbiologi, Universitetet i Oslo, P. B. 1064 Blindern, Oslo 3, Norway \\ ${ }^{2}$ Dunstaffnage Marine Laboratory, P. O. Box 3, Oban, Argyll, Scotland
}

\begin{abstract}
Isolation of groups of species indicative of pollution-induced effects on benthic communities has traditionally been based on subjective ecological expertise. A review of more general methods covering the use of diversity indices, computer based multivariate analyses is given. The conclusion drawn is that there are many drawbacks with these methods too and their so-called 'objectivity' is questioned. Using a modification of the log-normal distribution of individuals among species a new method is proposed which can be used to isolate objectively groups of species sensitive to pollution effects. An example is drawn from a time-series study on effects of organic enrichment on a soft-sediment community. The method suggested has a sound theoretical base, is simple to plot, utilizes all the data on individuals and species in a community and identifies groups of species that can be used in reduced scale monitoring programmes.
\end{abstract}

\section{INTRODUCTION}

Studies on the effects of pollutants on marine benthic communities use a variety of techniques aimed at separating the pollutant effect from natural environmental variability. Not least of the problems encountered in analysing data sets is the fact that most benthic assemblages contain large numbers of species, often well over 100. Many attempts to simplify these data sets have involved computations which integrate the number of species and individuals into a single index, the so-called diversity indices. Another approach is to use varieties of computer-based sorting methods (ordination and classification) to classify species or sites showing similar attributes into groups which can then hopefully be related to environmental and pollution gradients. Whereas diversity indices do not take into account species identity ordination and classification methods do. Species identity methods reach their zenith in the use of indicator species to identify environmental conditions.

All of the above methods suffer from major defects and another method based on a mathematical distribution of individuals among species (the lognormal distribution Gray and Mirza, 1979) was suggested as combining theoretical rigour with identification of sensitive species groups. Yet this method too suffers from drawbacks (see below). Here we consider critically the use of the above-mentioned methods to detect pollution-induced changes in communities and suggest a modification of the log-normal distribution as combining the merits of many of the above to provide on objective method of identifying suitable indicator species from complex data sets.

\section{DIVERSITY INDICES}

When originally proposed, diversity indices were used for quantifying ecological changes, such as comparing the diversity of different-sized islands or tropical to boreal regions (MacArthur, 1957, 1965). Their use in an applied context to assess effects of pollution is fashionable since the complex data of species and individuals per site is simplified into one index. Such an index has an appeal to engineers and legislators but obscures much information that may be useful in delimiting effects of pollution and may mislead the inexperienced observer by oversimplifying complex situations. 
Diversity as an ecological concept includes a number of factors whose identity and disparity are often ignored. This theoretical confusion led Hurlbert (1971) to go so far as to say that diversity per se does not exist' and the term should be abandoned. One of the major problems is that all the units (individuals) are assumed to be equal, yet sexes, development stages etc can play different functional roles in the community. Similarly species are assumed to be equivalent when they are clearly not. Diversity encompasses the species richness of a sample (the number of species in the sample); and the term richness is preferred since the exact number of species in a community is usually not known (Peet, 1974). However, the number of species alone cannot be reliably used to compare the relative wealth of species in communities since the number increases with sample size. The number of individuals per species is also an important component of diversity; Peet (1974) has called this aspect heterogeneity. The most widely used index measuring heterogeneity is the Shannon-Wiener Information Statistic (Shannon and Weaver, 1949) applied to ecological examples by Margalef (1968):

$$
H^{\prime}=-\sum_{I=1}^{s} p \mathrm{i} \log p \mathrm{i}
$$

where $p \mathrm{i}=n i / N ; \mathrm{s}=$ total number of species; ni $=$ number of individuals of $i$ th species; $N=$ total number of species.

Difficulty in understanding the relevance of the index is often expressed. It measures the uncertainty regarding the species of an individual taken at random from the sample. Using logs to the base 2 if there are 4 species $A, B, C, D$ each composed of 2 individuals per species the number of binary decisions $\left(\log _{2}\right)$ that are necessary to specify the species of the randomly chosen individual is $2(A B, C D$ dichtomy firstly and then $A$ or $\mathrm{B}$, or $\mathrm{C}$ or $\mathrm{D}$ secondly). The idea behind this method, therefore, is very similar to the probability of interspecific encounter (PIE) recommended as preferable by Hurlbert 1971.

Pielou (1975) has argued that the Shannon formula should be used on an infinite sample whereas the correct diversity index for a finite sample is Brillouins index, but Peet (1974) gives an example stressing the advantages of using the Shannon Index.

Another much used method of estimating diversity in the marine benthos is Sanders rarefaction technique (Sanders, 1968) where the number of species for a given number of individuals is estimated. The main problem with the rarefaction method is that it assumes that species/individuals relationships are similar in communities being compared and that the individuals are randomly distributed. Both assumptions rarely hold in benthic communities. The original formulation was biased and Hurlbert (1971) gives the expected number of species as

$$
E(s)=\sum_{t=1}^{s}\left\{1-\left(\begin{array}{c}
N-N_{i} \\
n
\end{array}\left(\begin{array}{l}
N \\
n
\end{array}\right)\right\}\right.
$$

where $N_{i}=$ number of individuals in the $i$ th species in the full sample; $n=$ sample size; $N=$ population size; $s=$ number of species.

Many more indices have been proposed and these are discussed fully in Peet (1974). Our comments will be confined to the above 2 methods.
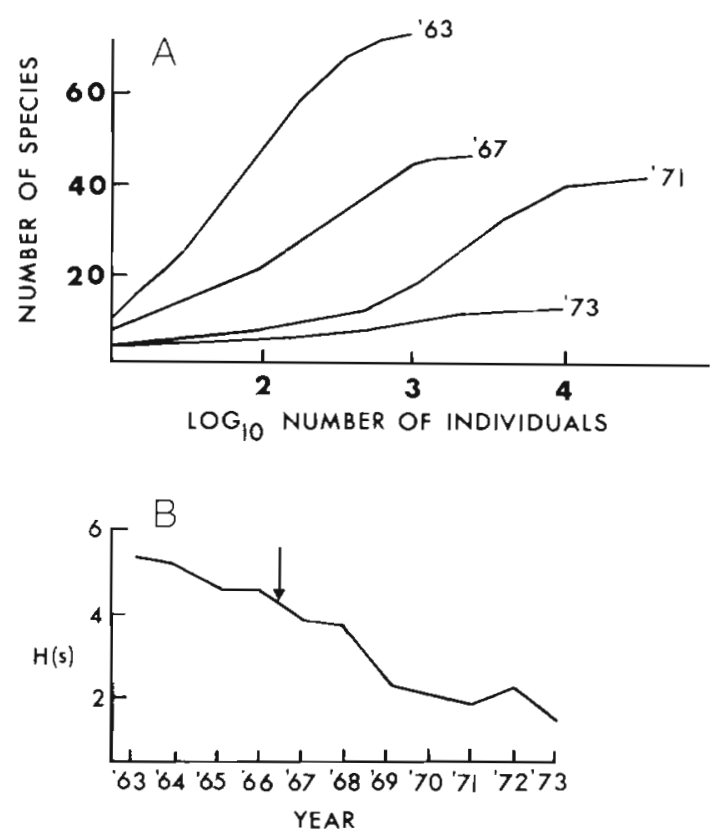

Fig. 1. Diversity indices calculated for time series data from Loch Eil, Scotland, in an area progressively affected by pulp mill effluent. (A) Rarefaction curves drawn for data from 1963 , prior to the incidence of pollution; 1967, $1 \mathrm{yr}$ after pollution began; 1971 and 1973, 5 and $7 \mathrm{yr}$ after onset of pollution. (B) Shannon-Wiener index [H(S)] plotted for each year from 1963 to 1973. Arrow: point where pollution began. (Afer Pearson, 1975)

Fig. 1 shows Shannon-Wiener and rarefaction curves for the same data sets from Loch Eil, an area polluted by pulp mill effluent. Clearly both methods show very similar trends. Similarly, Fig. 2 shows patterns of diversity in the eutrophic Oslofjord. Sewage, largely untreated, enters at the head of the fjord and due to the topography the inner eastern basin is stagnant. A clear gradient of pollution effects can be shown. From this example and the many similar ones reported in Pearson and Rosenberg's (1978) review it can be concluded that with gross changes diversity indices are useful. However, in Loch Eil (Fig. 1) pollution did not begin until 1966 prior to which there was an apparent falling trend under unpolluted conditions. Thus it is difficult 
to ascertain where an effect of pollution has occurred in a naturally variable environment. A statistically significant change in diversity pre and post pollution would not be apparent before 1970 at the Scottish site when the area was already clearly polluted. So although diversity methods can indicate trends they are not particularly sensitive. Furthermore, they do not take into account species identity.

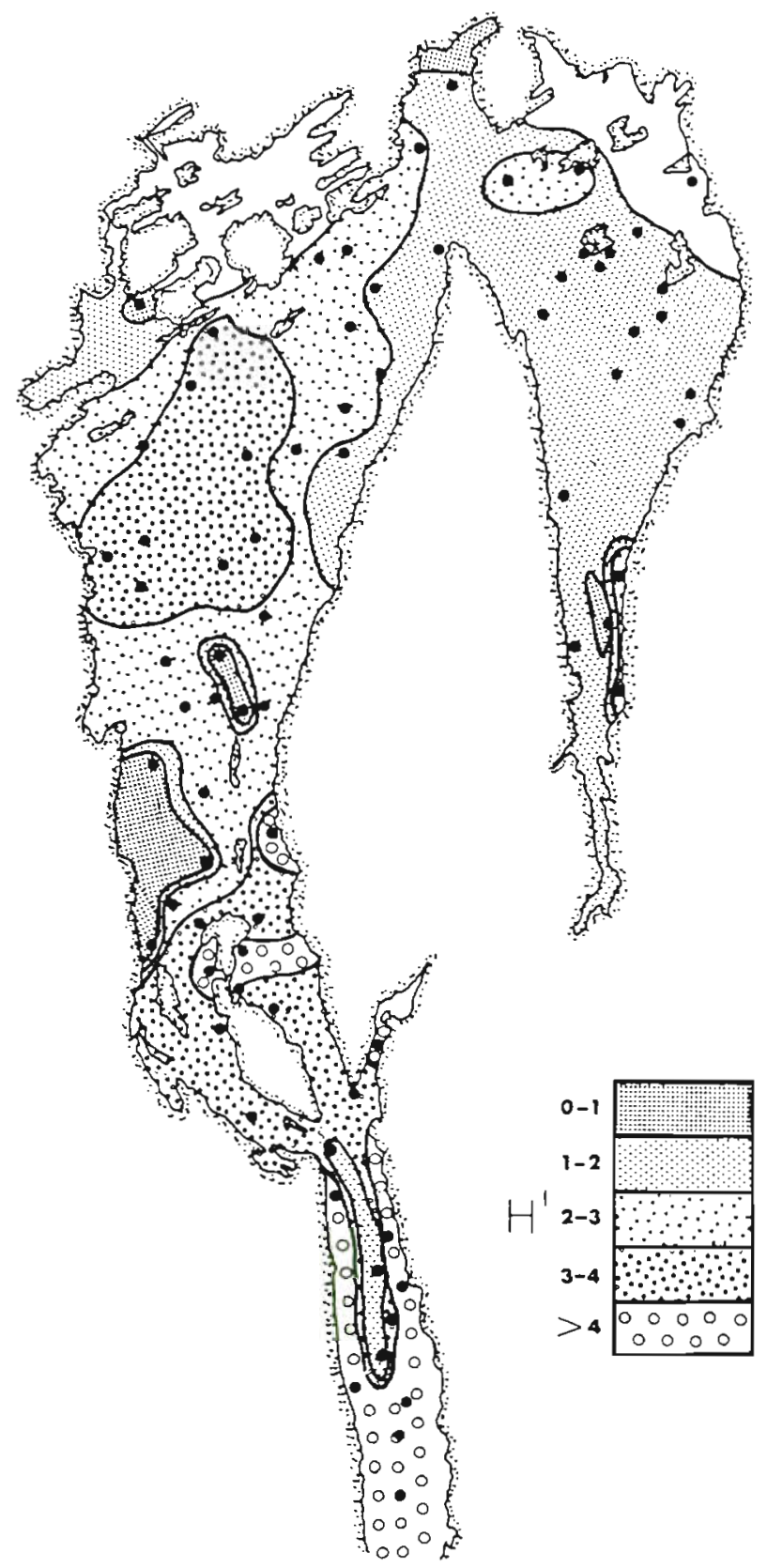

Fig. 2. Distribution of values of the Shannon-Wiener index $\left(\mathrm{H}^{\prime}\right)$ from data from the Oslofjord. The inner, eutrophic areas, affected by sewage pollution exhibit low values which increase progressively towards the outer entrance of the fjord

\section{MULTIVARIATE METHODS}

With the general availability of computers the use of multivariate techniques for analysing complex data sets has shown an explosive growth. Unfortunately the number of techniques in use has shown a similar increase. Clifford and Stephenson (1975) have given a good general introduction to methods and today easy access is available to multivariate packages (e.g. BMDP, SPSS, etc.). Two general techniques are available, ordination and classification. Ordination includes factor analyses of which principal components analysis is a subset. Here the method entails plotting the positions of sites or taxa on conventional Cartesian coordinates for attributes (e.g. numbers of individuals). The analysis seeks to extract from the ellipse usually present the position of the species (or sites) firstly along a line drawn through the points representing the maximum variance (Factor 1) and secondly a line, orthogonal to the first, recording the next dominant variance (Factor 2). With many site/ species groups the number of factors that can be extracted are large, but usually only the first 3 or 4 are used and typically these will 'explain' say 30,20 and $15 \%$ respectively of the variance. An attempt is then made to find environmental or biotic factors that can be correlated with the factors, since each site or species has a loading on each factor space. In practice this is exceedingly difficult to do and it is often impossible to find simple correlations. Thus although the methods have theoretical appeal in practice they are difficult to interpret. Classification methods seek to place either similar sites or taxa into groups with similar attributes and to link such groups together (agglomerative methods) or, based on the whole data set, to split the similar (or dissimilar) groups apart (divisive methods). The attributes used to form groups may be based on single characters (monothetic) or many characters (polythetic). In fact there are even more general categories and Clifford and Stephenson (1975) should be consulted for a more detailed discussion of such methods.

Both the above-mentioned methods have been used on the Oslofjord data and plots of the groups isolated by ordination and classification methods give very similar patterns (Fig. 3). Again, as with diversity calculations, the gradient in Oslofjord is clear and so the methods give acceptable results. Where gradients are less clear interpretation of patterns becomes more difficult.

The main advantage of using multivariate methods lies in their apparent objectivity since formal criteria and computer based sorting are used. However, objectivity is only partly true. Firstly, the data to be used is usually much too large for even big computers. With 

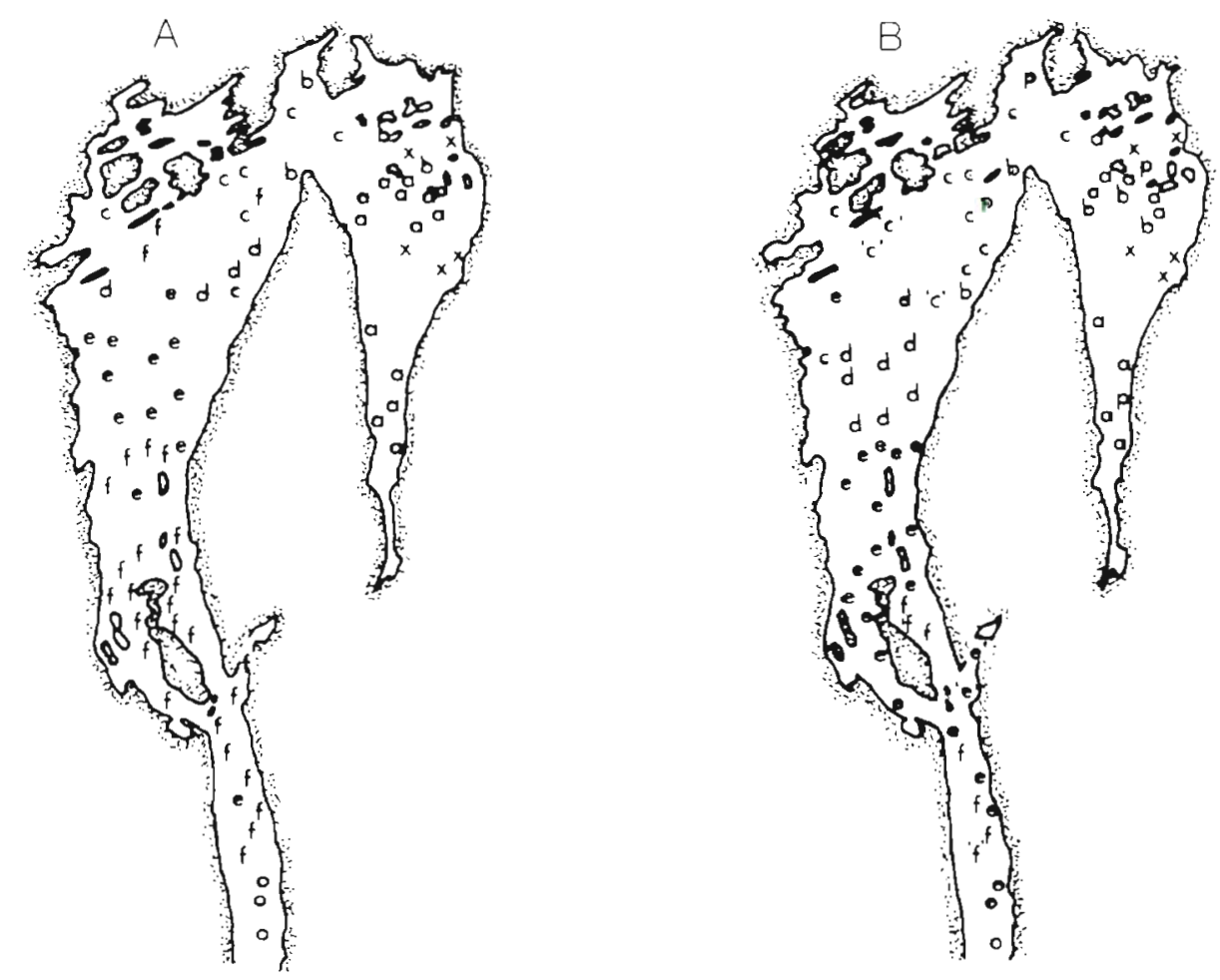

Fig. 3. Faunal groups in the Oslofjord as isolated by ordination (A) and classification (B) methods. a-f site groupings based on species. For details of species see Mirza and Gray (1981). o no sample; $\mathrm{x}$ very poor sample; brackets: probable site groups the Oslofjord data the data was reduced by objective criteria such as eliminating species occurring in less than 5 stations from 158 species from 76 sites to a $68 \times 68$ (species $\times$ sites) matrix. This was partly due to size restrictions of the computer used and partly because rare species present in small numbers can greatly affect the classification achieved. Often species that occur in less than $5 \%$ of sites are eliminated. When Stevenson et al. (1972) reanalysed Petersens' original data on which his benthic community was based such a species reduction eliminated one of the defining species Haploops tubicolor. (Stevenson and Cook, 1980 recently have examined species elimination methods in detail). Thus, one of the intrinsic properties of all communities, the presence of rare species is removed from the data used for further analysis.

After species reduction one has to decide on transformation methods to normalise the data. Again there is no uniform or agreed procedure; some authors advocate stringent transformation and others advocate no transformation.

The choice of similarity index or factoring method is highly varied, as is the sorting strategy in classification, and many options exist. Frequently, a number of methods are tried and results which are explainable are presented. The 'objectivity' of the method then has dissolved into objective sorting to get results which can be explained. One of us (J.S.G.) has 'standardised' his technique to principal factoring with iteration (SPSS package) on standardised data and classification using the Bray-Curtis dissimilarity index with groupaverage sorting again on standardised data.

So as with diversity indices multivariate methods have theoretical short-comings and are difficult to interpret in practice. Patterns of groups of species do, however, emerge which can be used in describing strong pollution gradients. The Oslofjord data shows that the basic patterns were similar with two multivariate methods and that groups of species occurring in the moderately polluted areas could be indentified. This is not possible with diversity methods.

\section{INDICATOR SPECIES}

Hill et al. (1975) have developed a multivariate analysis technique based on an ordination, (reciprocal averaging) which can be used to isolate indicator species. The technique has been applied to pinewood flora but has not been used to identify species indicative of pollution.

In freshwater biology it has long been the practice to identify species or groups of species which indicate grades of increasing pollution. Pearson and Rosenberg (1978) have extensively reviewed the use of indicator species in relation to organic enrichment in the marine environment. Their general conclusion was that in the most polluted areas characteristic species were those typical of the first stages of succession. Despite suggestions of 'universal indicators of organic pollution', 
species such as Capitella capitata occur in high densities in many other areas than those showing organic enrichment.

Pearson and Rosenberg (1978) did, however, indicate that in local areas groups of species characterising various stages of organic enrichment occurred. Such species groups are not universal but will vary in different geographical regions. The identification of such groups in both freshwater and marine environments is largely based on the experience of the ecologist(s) concerned.

What is needed therefore, to supersede dependance on such subjective expertise, is a method which covers the whole data set of rare and common species, can isolate in an objective manner groups of species sensitive to pollution-induced changes and is based on sound ecological principles.

\section{THE LOG-NORMAL DISTRIBUTION OF INDIVIDUALS AMONG SPECIES}

Fisher observed that there was a surprising regularity in the distribution of individuals among species in samples of a diverse range of communities. He was able to fit a mathematical distribution, the log-series which described this pattern (Fisher et al., 1943). In the log-series the group of rare species, represented by 1 individual per species is always dominant. In an analysis of many communities Preston (1948) found that this was usually not the case and he fitted a log-normal distribution, where individuals per species are divided into geometric classes (in this paper a scale of Class I $=1$ individual per species, Class II $=2-3$, Class III $=$ $4-7$. Class IV $=8-15$, etc. is used). This descriptive model has been found to yield an excellent fit to most large samples from heterogeneous communities (Gray, 1981). May (1975), however, has argued that this model is merely descriptive and has no biological meaning.

Accepting that the log-normal is a good fit to data on individuals and species from many communities Gray and Mirza (1979) proposed a method of detecting pollution-induced changes in benthic communities based on this distribution. In plots of the log-normal distribution the ordinate is of individuals per species on a geometric scale and the abscissa number of species. Since not all species are sampled the normal curve is never complete but is truncated to varying degreess. Preston (1962) found that as sample size increased more of the normal curve was exposed. The full species universe can be estimated by calculating an exact fit, either by using a long hand method (Bliss, 1966) or computer fits such as Gaussfit (Gauch and Chase, 1974). A complete normal distribution can be transformed into a straight line plot if instead of number of species on the abscissa cumulative number of species are plotted using probability paper. An alternative and better method is to transform the cumulative percent species to probits and to fit a linear regression. Because samples from natural communities show a truncated log-normal, probit plots will give a curve rather than a straight line since the transformation is too stringent over the first few points. An estimate of the total species number should be made first (Williams, 1964 gives methods for this). In practice, however, fits to the lognormal are never exact and the above error is usually relatively small. Fig. 4 (1963) shows data from an undisturbed community showing a good fit to the lognormal. Gray and Mirza (1979) used this graphical method and showed that in polluted areas instead of a

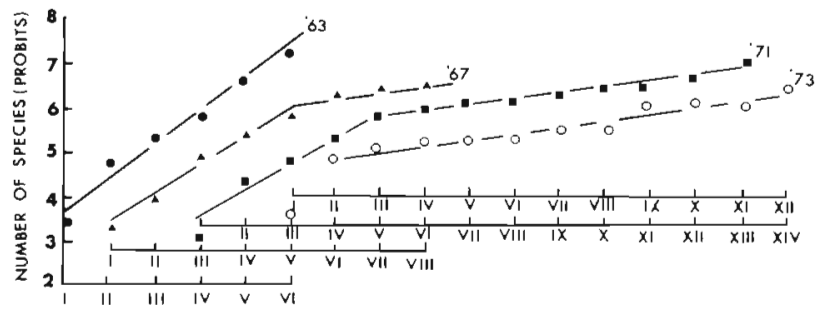

Fig. 4. Log-normal plots of data, transformed from cumulative percent species to probits, from the Loch Eil time series. Data from 1963, prior to onset of pollution; from 1967, 1 yr after pollution began; from 1971, 5 yr after pollution began; from 1973,7 yr after pollution began

single straight line a break and two lines occurred (Fig. 4: 1967, 1971). They suggested that this was due to some species increasing in abundance. After a period of time with heavy pollution the distribution returns to a straight line plot with a shallow slope and covering many geometric classes (Fig. 4: 1973). Gray and Mirza also pointed out that groups of species occurring at and just to the right of the break-point could be isolated, which were those most sensitive to pollution-induced changes (in Fig. 4, 1967 and 1971, Classes V and VI). The method has been found to be useful and has been applied in both general ecological studies (e. g. Hicks, 1980), and to pollution examples (e.g. Andrews and Richard, 1980, Gulliksen et al., 1980). However, the plotting method is relatively insensitive. This is due in part to the number of individuals per species being grouped into classes, thus underutilising many data points and in part to the problem of fitting of lines. The fit to a straight line is not perfect and deciding on whether one or two lines occur is often difficult. Whilst Preston (1980) has suggested other possible solutions Gray (1981) has refuted these ideas.

In seeking a biological explanation for the log-normal Ugland and Gray (1982) examined critically all the available theories and showed that the lognormal 


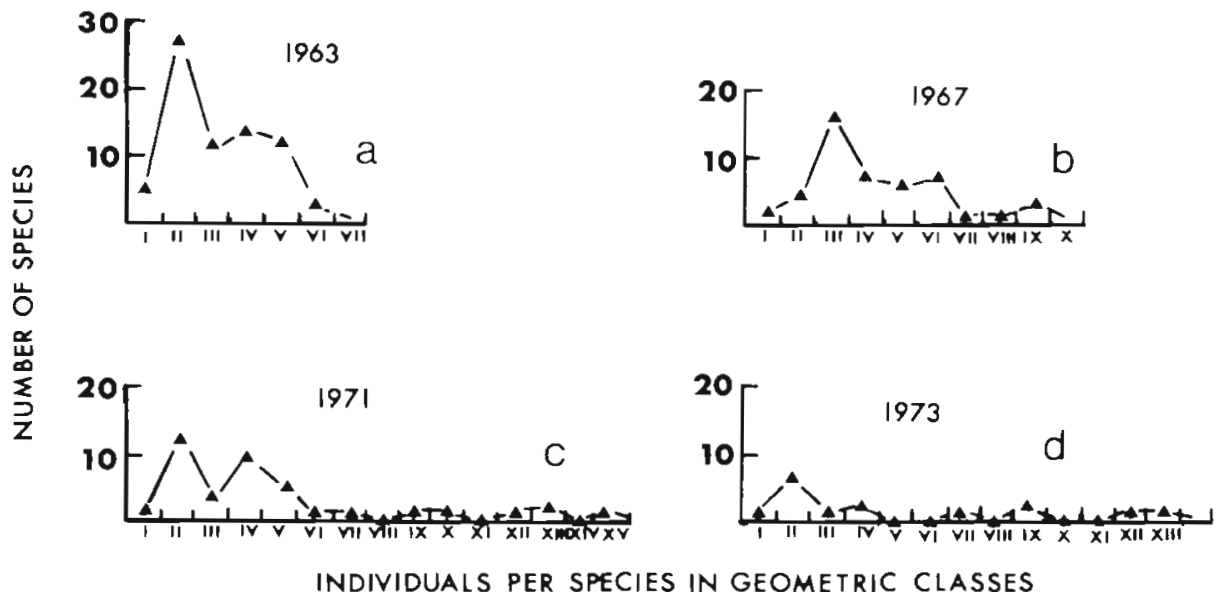

Fig. 5. Log-normal plots of the Loch Eil time series data plotted as number of species in each geometric abundance class $(\times 2)$. Classes range from Group 1 . species represented by a single individual; through Group V, species having between 16 and 31 individuals; to Group XV, species having between 16,584 and 33,169 individuals. 1963, prior to enrichment; 1967, 1 yr after pollution began; 1971, 5 yr after pollution: 1973,7 yr after pollution could be derived from fusing together 3 or more groups of binomially distributed individuals among species. They suggested that the 3 possible groups were of a group of rare species not well adapted to the habitat (often comprising 60 to $70 \%$ of the total species), a group of moderately well adapted species, and a group comprising few species which were well adapted to the habitat. The groups, it is suggested, represent an ecological and evolutionary equilibrium where, as the environment changes, groups of species better adapted increase in abundance and groups of species less well adapted decrease in abundance and may even become locally extinct. Organic enrichment disturbs the equilibrium and can be expected to lead to an increased abundance in those species which can utilise the changed conditions.

A complicating factor to this analysis in many benthic data sets will be the existance of pattern based on variation in species size or territorial spacing. Such inherent ecological variability will determine the frequency of occurrence of most species in undisturbed communities and be a component of their fitness to survive in that environment as represented by the numbers present in a given area. However, such patterns are also distorted by the disturbance caused by pollution and will therefore form part of the underlying change in abundance groups observed.

For a log-normal distribution, if, instead of plotting cumulative percent species on the abscissa the number of species is plotted one would expect a smooth bellshaped curve. The curve will always be truncated at the left-hand margin since the complete species universe is never sampled. Yet plots rarely show a smooth curve, the underlying component curves are usually apparent.

Fig. 5, taken from data on organic enrichment in a Scottish Loch (Pearson, 1975), shows (a) conditions prior to enrichment; (b) and (c) increasing enrichment; (d) heavy enrichment. This data clearly supports the contention that with enrichment the component curves become exposed as the total number of individuals in the sample increases. Similar data from a pollution gradient around Bergen (Norway), were shown in Ugland and Gray (1982). Thus by plotting each data point for individuals per species against number of species a more sensitive method of arriving at disturbance is obtained. In fact, the isolation of 2 log-normal distributions is precisely what is done in the plotting method described by Gray and Mirza (1979) for disturbed communities (e.g. Fig. 4: 1967, 1971); similar techniques are well known and widely used when attempting to separate cohorts from size-frequency distributions using probability paper (Harding, 1949). Thus it is apparent that the original log-normal curve which gives a reasonable fit to a straight line plot using cumulative percent is composed of 2 or more groups of species (e.g. 3 in Fig. 5: 1963).

Yet perhaps the most important aspect of this method is that an 'indicator' group can be isolated objectively. Two changes are apparent. Firstly, the groups became more distinct with enrichment and 'move' along the ordinate as dominance increases. Secondly, the mode of the 'rare' group of species (closest to the abscissa) becomes progressively reduced as rare species are eliminated. If one records the identify of the second group of species, the moderately common species, a group sensitive to enrichment can be established. This group of species will vary from region to region and thus is theoretically more acceptable than naming universal indicator species. From the theory presented above some species within the group will be increasing in abundance and some decreasing and abundances must be compared with the prepollution state. The common group of species (at Class VIII in 1963, Fig. 5) are also increasing but they are fewer in number (smaller area) and occur in very large numbers and are thus time consuming to monitor. Monitoring of the second group is the most realistic approach. 
Table 1. Analysis of data from (Pearson, 1975; his Table 11) listing species in abundance groups IV to VI, with an indication of their comparative abundance arrows indicating increasing or decreasing relative to succeeding years (status) and subjectively assessed position along a gradient or organic enrichment (successional phase)

\begin{tabular}{|c|c|c|c|c|c|c|c|c|c|}
\hline & \multicolumn{3}{|c|}{ Group IV (8-15) } & \multicolumn{3}{|c|}{ Group V (16-31) } & \multicolumn{3}{|c|}{ Group VI (32-63) } \\
\hline & Species & $\begin{array}{l}\text { Sta- } \\
\text { tus }\end{array}$ & $\begin{array}{l}\text { Succes- } \\
\text { sional } \\
\text { phase }\end{array}$ & Species (Group) & $\begin{array}{l}\text { Sta- } \\
\text { tus }\end{array}$ & $\begin{array}{l}\text { Succes- } \\
\text { sional } \\
\text { phase }\end{array}$ & Species & $\begin{array}{l}\text { Sta- } \\
\text { tus }\end{array}$ & $\begin{array}{c}\text { Succes- } \\
\text { sional } \\
\text { phase }\end{array}$ \\
\hline \multirow{11}{*}{1963} & Spiophanes kroyeri & $\uparrow$ & 2 & Sphaerodorum gracilis & $\uparrow$ & $1 / 2$ & Lepidopleurus asellus & $\downarrow$ & \\
\hline & Lipobranchius jeffreyi & $\uparrow$ & & Prionospio cirrifera & $\uparrow$ & 2 & Lucinoma borealis & $\uparrow$ & 2 \\
\hline & Scalibregma inflatum & $\uparrow$ & 1 & Euclymene oerstedi & $\uparrow$ & & Terebellides stroemi & $\uparrow$ & 1 \\
\hline & Praxillella affinis & $\uparrow$ & 1 & Myriochele heeri & $\downarrow$ & 1 & & & \\
\hline & Praxillura longissima & $\uparrow$ & 2 & Oweria fusiformis & $\uparrow$ & & & & \\
\hline & Ampharete acutifrons & $\uparrow$ & 2 & Nucula sulcata & $\downarrow$ & 1 & & & \\
\hline & Ameana trilobata & $\uparrow$ & 1 & Astarte elliptica & $\downarrow$ & & & & \\
\hline & Eupolymnia nesidensis & $\downarrow$ & 1 & Thyasira flexuosa & $\uparrow$ & 2 & & & \\
\hline & Golfingia procera & 1 & 1 & Amphiura filiformis & $\uparrow$ & 2 & & & \\
\hline & Corbula gibba & 1 & $1 / 2$ & Labidoplax buski & $\uparrow$ & 2 & & & \\
\hline & Thracia sp. & $\downarrow$ & 1 & & & & & & \\
\hline \multirow{7}{*}{1967} & Scoloplos amiger & $\downarrow$ & 2 & Cirratulus cirratus & $\uparrow$ & 1 & Pholoe minuta & $\uparrow$ & $2 / 3$ \\
\hline & Spiophanes kroyeri & $\downarrow$ & 2 & Praxillella affinis & $\downarrow$ & 2 & Sphaerodorium gracilis & $\downarrow$ & $1 / 2$ \\
\hline & Myriochele heeri & $\downarrow$ & 1 & Lagis koreni & $\uparrow$ & 1 & Glycera alba & $\uparrow$ & 1 \\
\hline & Terebellides stroemi & $\downarrow$ & 1 & Nucula sulcata & $\downarrow$ & 2 & Goniada maculata & $\rightarrow$ & 2 \\
\hline & Golfingia procera & $\downarrow$ & 1 & Mya arenaria & $\downarrow$ & 2 & Myrtea spinifera & $\uparrow$ & 2 \\
\hline & Scutopus ventrolineatus & $\downarrow$ & & Amphiura filiformis & $\downarrow$ & 1 & Lucinoma borealis & $\uparrow$ & 2 \\
\hline & Astarte elliptica & $\downarrow$ & & Ophiura albida & $\downarrow$ & & Corbula gibba & $\uparrow$ & $1 / 2$ \\
\hline \multirow{9}{*}{1971} & Kefersteina cirrata & $\downarrow$ & 2 & Ceriantharia & $\downarrow$ & 3 & & & \\
\hline & Paraonis gracilis & $\downarrow$ & 3 & Anaitides groenlandica & $\uparrow$ & 3 & & & \\
\hline & Polydora quadrilobata & $\downarrow$ & 2 & Eteone longa & $\downarrow$ & & & & \\
\hline & Chaetozone setosa & $\downarrow$ & & Owenia fusiformis & $\downarrow$ & 2 & & & \\
\hline & Cirratulus cirratus & $\downarrow$ & & Lagis koreni & $\downarrow$ & & & & \\
\hline & Pherusa plumosa & $\downarrow$ & 2 & & & & & & \\
\hline & Thyasira flexuosa & $\downarrow$ & 2 & & & & & & \\
\hline & Myrtea spinifera & $\downarrow$ & 2 & & & & & & \\
\hline & Lucinoma borealis & $\downarrow$ & & & & & & & \\
\hline \multirow{2}{*}{1973} & Eteone longa & $\downarrow$ & 3 & & & & & & \\
\hline & Modiolus sp. & $\uparrow$ & & & & & & & \\
\hline
\end{tabular}

Since this data set has already been subjected to detailed analysis by one of us (Pearson, 1975) using ecological experience the new method can be tested against the earlier analysis.

\section{IDENTIFICATION OF GROUPS OF INDICATOR SPECIES}

If we take the second group of species as being composed of those in abundance Groups IV (8-15) V (16-31) and VI (32-63) then an examination of those species occurring in these groups in the data set presented in Fig. 5 is instructive. Table 1 lists the species in these groups for each of the 4 yr selected, together with an indication of whether each species is increasing or declining in abundance in relation to the subsequent sampling period (designated Status in the table). Previous analysis of the data (Pearson, 1975) provided a subjective list of species regarded as characteristic of different phases of species succession along a hypothetical gradient of organic enrichment. The succession phase ascribed to those species previously listed which also appear as members of Groups IV to VI is also given in the table. Thus many of the species subjectively selected as characteristic of different successional phases along a gradient of organic pollution appear in Groups IV to VI. Moreover, their status in terms of increasing or decreasing abundance relative to succeeding years is of significance in relation to their abundance grouping in any particular year. In 1963, of the 11 species appearing in Group IV, 9 were present in greater numbers in succeeding years. In Group V, 7 out of 10 later increased; in Group VI, 2 out of 3. Organic enrichment of the system began in 1966 and in the following year only 7 species occurred in Group IV; all were decreasing compared with later years. Seven species also appeared in Group $V$ of which 5 later decreased, whereas in Group VI, 5 of the seven species recorded later increased. Four years 
later in 1971, the 9 species appearing in Group IV all subsequently declined, and of the 5 appearing in Group V 4 subsequently declined. No species appeared in abundance Group VI in that year, the more common species being then present in greater abundance in Groups IV to XV as pollution increased. In 1973, when the area was strongly polluted, only 2 species occurred in Group IV and none in Groups V and VI. The changing status of the individual species present in these abundance groups from year to year is also of interest. In 1963 the majority of the species appearing in Group IV were subjectively identified as characteristic of the normal unpolluted community in the area. However, 4 species belonging to the genera Spiophanes, Ampharete, Praxillura and Corbula were characterised as typical of the semi-polluted or Phase 2 situation; in Group V, 5 of the 10 species present, members of Sphaerodorum, Prionospio, Thyasira, Amphiura and Labidoplax were typified as Phase 2 species. By 1967, a year after pollution started, 4 of these 8 species were found in Group V or VI, 2 others in higher abundance groups, and 2 had declined below Group IV. In 1973, of these 8 species only Thyasira flexuosa was still present in Groups IV to VI and its numbers were declining rapidly. It seems apparent therefore that in the years preceding pollution and in the period immediately following pollution the species present in Group V, i. e. those occurring then in numbers of between 16 and 32 in the samples, were the species which generally exhibited positive sensitivity to the environmental change taking place and which subsequently increased rapidly in numbers. The species most adversely affected tended to occur in the lower abundance groups, i.e. Group IV or lower, but their low numbers and ephemeral appearance in the time series makes their utility as indicators of community change questionable. In the year following the start of pollution 6 of the 7 species occurring in abundance Group VI were later subjectively identified as characteristic of moderately or highly polluted conditions.

Thus an analysis of the data set by a plot of number of individuals per species against number of species to identify the incipient spread of abundance groups following a pollution related distortion of the community, combined with a closer analysis of the species comprising those groups (usually V and VI) where change is most rapid along a spatial or temporal gradient provides a simple method for identifying those species in the community which will profitably repay further intensive study. The method relies on a comprehensive sample of species and individuals and cannot be used on data from a single sample. However, the groups isolated comprise several species, the method is robust to sampling variability since the groups remain dis- tinct. The groups are not artificial but are real properties of the community structure.

This modification of Gray and Mirza's (1979) method of analysing the lognormal distribution of individuals among species offers a considerable improvement over other methods currently in use: It has a sound theoretical base; is simple to plot and does not involve complex mathematical or statistical methods; utilises all the data on individuals and species in a community; and gives objectively the identity of species sensitive to pollution which can be used in future reduced-scale monitoring programmes.

In a further paper we will demonstrate the wider utility of this model in a greater variety of communities.

\section{LITERATURE CITED}

Andrews, M. J., Richard, D. (1980). Rehabilitation of the Inner Thames Estuary. Mar. Pollut. Bull. 11: 327-331

Bliss, C. I. (1966). An analysis of some insect trap records. In: Patil, G. S. (ed.) Proceedings of international symposium on classical and contagious discrete distributions (Montreal, 1963). Statistical Publishing Co., Calcutta 35, pp. 385-397

Clifford, H. T., Stephenson, W. (1975). An introduction to numerical classification, Academic Press, London

Fisher, R. A., Corbet, A. S., Williams, C. B. (1943). The relation of the number of species and the number of individuals in a random sample of an animal population. J. Anim. Ecol. 12: $42-58$

Gauch, H. G., Jr., Chase, G. B. (1974). Fitting the Gaussian curve to ecological data. Ecology 55: 1377-1381

Gray, J. S. (1979). Pollution-induced changes in populations. Phil. Trans. R. Soc. Lond. (Ser B.) 286: 545-561

Gray, J. S. (1981). Detecting pollution induced changes in communities using the log-normal distribution of individuals among species. Mar. Pollut. Bull. 12: 173-176

Gray, J. S., Mirzd, F. B. (1979). A possible method for detecting pollution induced disturbance on marine benthic communities. Mar. Pollut. Bull. 10: 142-146

Gulliksen, B., Haug, T., Sandnes, O. K. (1980). Benthic macrofauna on new and old grounds at Jan Mayen. Sarsia 65: $137-148$

Harding, J. P. (1949). The use of probability paper for the graphical analysis of polymodal frequency distributions. J. mar. biol. Ass. U. K. 28: 141-153

Hicks, G. R. F. (1980). Structure of phytal harpactiocoid copepod assemblages and the influence of habitat complexity and turbidity. J. exp. mar. Biol. Ecol. 44: 157-192

Hill, M. O., Bunce, R. G. H., Shaw, M. W. (1975). Indicator species, a divisive polythetic method of classification, and its application to a survey of native pinewoods in Scotland. J. Ecol. 63: 597-613

Hulbert, S. N. (1971). The non-concept of species diversity. Ecology 53: 577-586

MacArthur, R. (1957). On the relative abundance of bird species. Proc. natn. Acad. Sci. U.S.A. 43: 293-295

MacArthur, R. (1965). Geographical ecology, Harper \& Row, New York

Margalef, R. (1968). Perspectives in ecological theory, University Chicago Press, Chicago, Illinois

May, R. M. (1975). Patterns of species abundance and diversity. In: Cody, M. L., Diamond, J. M. (eds.) Ecology and 
evolution of communities. Belknap Press, Cambridge Mass, pp. $81-170$

Mirza, F. B., Gray, J. S. (1981). The fauna of benthic sediments from the organically enriched Oslofjord, Norway. J. exp. mar. Biol. Ecol. 54: 181-207

Pearson, T. H. (1975). The benthic ecology of Loch Linnhe and Loch Eil, a sea-loch system on the west coast of Scotland. IV. Changes in the benthic fauna attributable to organic enrichment. J. exp. mar. Biol. Ecol. 20: 1-41

Pearson, T. H., Rosenberg, R. (1978). Macrobenthic succession in relation to organic enrichment and pollution of the marine environment. Oceanogr. Mar. Biol. Ann. Rev. 16 229-311

Peet, R. K. (1974). The measurement of species diversity. Ann Rev. Ecol. Syst. 5: 285-307

Pielou, E. C. (1975). Ecological diversity, John Wiley, New York

Preston, F. W. (1948). The commonness and rarity of species Ecology 29: 254-283
Preston, F. W. (1962). The canonical distribution of commonness and rarity. I. Ecology 43: 185-215

Preston, F. W. (1980). Non-canonical distributions of commonness and rarity. Ecology 61: 88-97

Sanders, H. L. (1968). Marine benthic diversity: a comparative study. Am. Nat. 102: 243-282

Shannon, C. E., Weaver, W. (1949). The mathematical theory of communication, University Illinois Press, Urbana

Stephenson, W., Cook, S. D. (1980). Elimination of species before cluster analysis. Aust. J. Ecol. 5: 263-273

Stephenson, W., Williams, W. T., Cook, S. G. (1972). Computer analysis of Petersens original data on bottom communities. Ecol. Monogr. 42: 387-415

Ugland, K. I., Gray J. S. (1982). Lognormal distributions and the concept of community equilibrium. Oikos, in press

Williams, C. B. (1964). Patterns in the balance of nature and related problems in quantitative ecology, Academic Press, New York

This paper was submitted to the editor; it was accepted for printing on May 14, 1982 